\title{
FRAUDE E RESPONSABILIDADE NAS PESQUISAS CTS: A INVESTIGAÇÃO DAS APARÊNCIAS
}

\author{
Simone Moraes STANGE ${ }^{1}$ \\ Carlos Roberto Massao HAYASHI ${ }^{2}$
}

RESUMO: Na contemporaneidade, percebe-se o elevado índice de cotejamento da informação com os processos acadêmicos de investigação. A era digital disponibiliza uma ampla área de atuação entre culturas, teorias e modos de pensamento, democratizando o acesso aos pensamentos e ideias, viabilizando a disseminação do conhecimento e, também, possibilitando a promoção de práticas inconsequentes baseadas no plágio. O texto constitui um artigo de revisão de literatura no domínio CTS que analisa as condições de possibilidade da ciência e do sujeito por ela constituído no debate sobre as noções de fraude e de responsabilidade que os mesmos possuem. A pesquisa tem o objetivo de elucidar quais são as implicações que o plágio prescreve para a linha de atuação da ciência e da tecnologia. Logo, o trabalho divide-se em três momentos: inicialmente, buscar-se-á explicitar os conceitos de ética, de responsabilidade e de plágio, construindo aparato para os dois momentos seguintes, o levantamento das principais consequências do fim da autonomia e da autoria científica, na demonstração do descrédito dos sujeitos cognitivos e, no terceiro momento, apresentar as possibilidades de repensar instrumentos de reordenamento das práticas acadêmicas que busquem, significativamente, serem apropriadas de modo autêntico, inovador e baseada no desenvolvimento social das pesquisas em CTS.

PALAVRAS-CHAVE: Ciência-Tecnologia-Sociedade (CTS). Pensamento crítico. Responsabilidade social da ciência.

\section{Introdução}

$\mathrm{Na}$ contemporaneidade, percebe-se o elevado índice de cotejamento da informação com os processos acadêmicos de investigação. A era digital disponibiliza uma ampla área de atuação entre culturas, teorias e modos de pensamento, democratizando o acesso aos pensamentos e ideias, viabilizando a disseminação do conhecimento e, ao mesmo tempo, possibilitando a promoção de práticas inconsequentes que degeneram a imagem da social da Ciência, baseadas no plágio e na apropriação ilícita de conhecimentos produzidos por terceiros sem promover o devido crédito.

\footnotetext{
${ }^{1}$ Doutoranda em Ciência, Tecnologia e Sociedade. UFSCAr - Universidade Federal de São Carlos - PósGraduação em Ciência, Tecnologia e Sociedade. São Carlos - SP - Brasil. 13565-905. Professora Mestra na Secretaria do Estado da Educação de Santa Catarina - simonestangue@gmail.com

${ }^{2}$ Doutor em Educação. UFSCAr - Universidade Federal de São Carlos -Pós-Graduação em Ciência, Tecnologia e Sociedade - Departamento de Ciência da Informação. São Carlos - SP - Brasil. 13565-905. massao@ufscar.br
} 
Silva (2008) destaca a necessidade de repensar mecanismos que não prejudiquem o valor efetivo das relações entre autoria e autonomia/projetos e ações na esfera universitária, constituinte basilar do desenvolvimento credível das ciências. No mesmo sentido, Veludo-de-Oliveira et al. (2014) demonstram empiricamente que a problemática ética do plágio ganha proporções preocupantes quando analisados os discursos e dados de estudantes universitários e a violação dos direitos do autor proporcionadas pelas suas produções textuais. Além disso, os autores apontam para o fato das práticas acadêmicas desonestas constituírem e consolidarem a cultura do plágio e da perda da integridade acadêmica dos estudantes, determinando a falta de credibilidade dos estudos e das ciências.

Uma das heranças da Idade Moderna proporcionada pelo pensamento cartesiano racionalista encontra-se na valorização exacerbada da consideração pelos profissionais que tenham sido perpassados pela conjuntura científica no seu processo de formação. Espera-se deles a capacidade de prospecção acadêmica autônoma, com a possibilidade real da produção de conhecimentos ou de teses originais que respeitem as referências da base de sua especialidade, viabilizando o progresso científico, tecnológico e social. Todavia, com o aproveitamento ilegal de expressões de ideias alheias, a estrutura das mudanças paradigmáticas torna-se obsoleta, prejudicando o aperfeiçoamento do conhecimento e perdendo completamente a confiança na atividade dos centros de pesquisa universitária.

Assim, percebe-se que a responsabilidade científica das investigações é amplamente questionada na estruturação epistemológica do campo de conhecimento e da relevância prática, sobretudo acerca das repercussões negativas sobre a sociedade. Consequentemente, faz-se primordial repensar as práticas científicas e formativas que visem o esclarecimento e a conscientização das consequências sociais, políticas e culturais ocasionadas pelo desnorteamento ético da divulgação das pesquisas.

Para esse escopo, o trabalho será dividido em três momentos centrais: inicialmente, buscar-se-á explicitar os conceitos de ética, de responsabilidade e de plágio, construindo aparato para os dois momentos seguintes, o levantamento das principais consequências do fim da autonomia e da autoria científica, na demonstração do descrédito dos sujeitos cognitivos e, no terceiro momento, apresentar as possibilidades de repensar instrumentos de reordenamento das práticas acadêmicas que busquem, significativamente, serem apropriadas de modo autêntico, inovador e baseada no desenvolvimento social das pesquisas em CTS. 


\section{Agências de fomento, plágio e responsabilidade na comunicação científica}

A comunicação científica constitui-se no século XXI como um dos relevantes processos de socialização de pesquisas acadêmicas, angariando condições de possibilidade da eleição aprofundada e criteriosa de novos objetos de investigação. Constata-se, todavia, que as discussões universitárias sofrem consequências sérias resultantes das práticas inconsequentes de plágio disseminadas no âmbito geral de todas as Ciências.

Nesse panorama, faz-se fundamental a discussão sobre as complexas relações entre produção dos saberes científicos e seu processo de divulgação, relevando a eticidade dos sujeitos que compõem a comunidade acadêmica - cientistas, estudantes de graduação e de pós-graduação e editores de revistas especializadas - no que tange ao dilema moral da prática do plágio.

Segundo Russo (2014), o plágio é definido na contemporaneidade como desvio de conduta moral, civil e penal, pelo qual se cotejam ponderações de terceiros omitindose deliberadamente, ou por negligência, a referência dos mesmos no trabalho final. Tal apropriação fraudulenta possui raízes das mais diversas naturezas e motivações, demonstrando um agravante sintoma da propensão ética das pesquisas desenvolvidas.

Outra problemática sobre a concepção de plágio diz respeito ao paradigma da propriedade intelectual. Vasconcelos (2007) no texto "O plágio na comunidade científica: questões culturais e linguísticas" sustenta que as relações estabelecidas no meio acadêmico pelos cientistas defendem avidamente a condenação da cópia como sinônimo da defesa da originalidade do trabalho publicado. Além disso, a criminalidade do plágio representaria o endosso da autoria e de seus eventuais méritos na publicação autêntica. De acordo com esse texto, há uma cultura da originalidade implícita na comunicação científica, diretamente determinada pela capacidade linguística e investigativa dos autores.

Nessa perspectiva, torna-se salutar referendar que as transformações culturais provenientes das influências digitais e da flexibilização do acesso ao conhecimento modificam consideravelmente os modos de produção, validação e difusão das pesquisas científicas, dos seus saberes produzidos e, sobretudo, do uso formativo dos instrumentos de estudos acadêmicos. A cultura e os as ações práticas que permeiam o campo acadêmico enfrentam um processo volátil de discussão e socialização dos resultados científicos, demarcados por complexidades elevadas no âmbito político e epistemológico. 
De um lado, existe o desenvolvimento de práticas de produção de conhecimentos integrados, formados pela coparticipação de cientistas e especialistas, colaborando ativamente para o aprofundamento de questões fundamentais ao panorama científico. Por outro, a elevação das exigências das agências de fomento no que concerne à qualidade das discussões e, principalmente, ao número de publicações acadêmicas anuais, dificultando o aprofundamento de investigações.

Por esses motivos, Silva (2008) destaca a necessidade de repensar mecanismos que não prejudiquem o valor efetivo das relações entre autoria e autonomia de projetos e ações de intervenção na esfera universitária, pois a mesma apresenta-se como constituinte fundamental do desenvolvimento credível das ciências.

Em contraponto ao quadro dilemático exposto, aponta-se para o fato de que vários documentos oficiais estabelecidos pelas agências brasileiras de fomento à pesquisa disponibilizam comissões que orientam e determinam quais práticas de verificação da idoneidade da pesquisa devem prevalecer (BRASIL, 2014; CNPq, 2014a; CNPqb; FAPESP, 2014). Defende-se a elucidação de incongruências registradas nos textos científicos de circulação mundial, com o propósito de corroborar a atividade científica em seu aparato elementar de renovação e aperfeiçoamento de paradigmas da comunidade acadêmica. Evidencia-se, portanto, que os fenômenos científicos e tecnológicos possuem implicações sociais determinantes das diretrizes sociais, fundamentalmente no que se referem à viabilização da credibilidade dos métodos de pesquisa.

Nessa direção, a objetividade do diálogo científico torna-se ameaçada na medida em que a desonestidade constituir-se como hábito de pesquisadores e estudantes em processo de formação. Toda elaboração teórica crível necessita de condições que promovam pareceres provenientes das tentativas de solução aos problemas investigados, e não se limite a repetição irracional de informações desconexas.

A isenção da reflexão e do surgimento de contrapontos dialógicos, retificadores das hipóteses científicas defendidas, desenvolvem consequências drásticas não apenas ao indivíduo infrator moral. De modo acentuado, a comunidade global perde oportunidades relevantes de melhorias nas políticas públicas, deixando de oferecer condições de superação das desigualdades e atritos sociais, bem como limitando o crescimento acerca da realidade dos indivíduos sociais por ela envolvidos.

No artigo "Intertextualidade ou plágio? - considerações teórico-práticas” Castro e Olival (1990) assinalam que os conceitos de plágio, imitação e citação possuem 
mudanças acentuadas no transcorrer da história e da pluralidade de culturas. Os autores lembram que inclusive a noção de tradução já foi considerada originalidade e aperfeiçoamento textual na sociedade romana e medieval. Por esses motivos, defende-se que a apropriação indevida de materiais produzidos por outros autores podem ser corrigidos, uma vez que essa ação indevida é, em muitos casos, resultante da ignorância dos procedimentos científicos de relatar e diferenciar conclusões próprias de contribuições das fontes pesquisadas.

Nesses casos, torna-se vital esclarecer as regras científicas pautadas na ideologia social e na estrutura intertextual que o código da divulgação científica preconiza. Assinala-se também a relevância da honestidade intelectual nas práticas acadêmicas cotidianas, expressando o esforço constante de demonstração da autoria das fontes utilizadas. Aliado a uma autocorreção honesta das ponderações alcançadas, o plágio pode ser rebatido como uma conduta que agride os princípios da cidadania, desrespeitando as condições de convivência e de cooperação interpessoal.

Russo (2014) aprofunda o debate sobre o plágio na contemporaneidade ao defender a responsabilidade do pesquisador como um valor da Ciência. A autora argumenta sobre a proposta de promover a ética e a integridade da pesquisa pelo intermédio da coletividade imputada a toda comunicação de cunho acadêmico. A demonstração da nocividade social acarretada pelas fraudes dos resultados de qualquer campo do conhecimento garantiria, de acordo com Russo (2014, p.196, grifo do autor), o compromisso recíproco entre cientista e sociedade.

Tornamo-nos mais responsáveis quando temos mais consciência dos atos que praticamos e de suas consequências. Deveríamos pensar não só em instaurar câmara de integridade de pesquisa, mas promover com maior frequência o debate sobre ciência, responsabilidade científica, garantindo a presença de cientistas, alunos, instituições, editores, juristas e também demais atores da sociedade. Esse tipo de debate ainda é bastante tímido nas instituições de pesquisas e mesmo nos grandes congressos temáticos raramente se vê espaço para debater questões de ética e integridade, sendo todas as chamadas voltadas unicamente para trabalhos de análise de dados. Ao mesmo tempo, os valores dados aos critérios de publicação científica e classificação de autores deveriam urgentemente voltar-se para o quesito qualidade ao invés de quantidade.

No sentido oposto, é possível afirmar que as condutas nocivas do plágio alimentam a desconfiança sobre a legitimidade do trabalho científico, seja a imagem dos atores que a compõem, ou pela descrença das promessas do progresso científico proferidas desde o projeto iluminista ocidental. As consequências do descrédito 
científico podem tramitar pelas mais diversas naturezas de pseudociências: medicinas paralelas, fenômenos paranormais outras falsas crenças pertencentes ao universo do conhecimento popular, historicamente preterido pela organização racional do método científico. Por isso, a perda progressiva da confiança científica acarretada pelas práticas ilícitas do plágio prejudica o funcionamento da estrutura básica da sociedade, além de contribuir para o enfraquecimento dos dois fundamentos da investigação científica analisados na próxima seção, a autonomia da concatenação das hipóteses levantadas e a potencialidade de ser sujeito das conclusões no processo autoral de resultados.

\section{Autonomia, autoridade e autoria científica}

A perspectiva científica contemporânea enfrenta mudanças dos padrões da atividade do cientista e da divulgação de seus resultados. A valorização da autoria como critério determinante na avaliação do pesquisador pelas agências de fomento ratifica uma postura epistemológica pautada no sujeito e na sua capacidade de construção de relações críticas entre o objeto de pesquisa e sua visão de mundo.

Nesse sentido, pode-se afirmar a existência de uma relação intrínseca entre ética e responsabilidade na pesquisa acadêmica, demonstrando que o uso da informação é marcadamente complexo e demanda posicionamentos sérios de pesquisadores e de estudantes para que possam se preparar ao combate contra toda conduta que seja prescrita pela cópia ilícita de relatos acadêmicos. A responsabilidade científica das investigações torna-se um problema de âmbito não meramente acadêmico, mas político e social. O respeito pelo direito de propriedade do conhecimento desenvolvido academicamente torna-se a expressão máxima da autonomia do cientista no que concerne ao seu processo produtivo.

Steven Shapin, no texto intitulado Science and the Modern World (2008) apresenta diversos fatores que interligam as mudanças dos paradigmas que constituem as práticas científicas com os pressupostos da sociedade moderna e seu processo de informatização do conhecimento e de globalização das relações culturais e econômicas. Para Shapin (2008), torna-se inegável a influência das relações do capital e do senso de produtividade nos procedimentos epistemológicos e nas suas hierarquizações. Por consequência, as Ciências Naturais prevalecem sobre as demais, inclusive na metodologia e nos critérios institucionais de avaliação da produtividade.

Nessa linha argumentativa, Shapin (2008) apresenta elementos de reflexão sobre a autoridade pública do conhecimento científico pautada na problematização da função 
do cientista no mundo moderno. Defende-se a diferenciação entre cientista e o sujeito responsável por promover avanços tecnológicos pontuais (technologist) partindo dos conceitos de autonomia e integridade da atividade do cientista. Shapin defende que a transformação do conhecimento em propriedade patenteável acarreta no esfacelamento da independência do cientista com a autoridade de sua atividade, por vezes esvaziada ou mesmo reduzida à invisibilidade.

Assim, a autoridade do cientista recebe o ônus do progresso moderno da tecnologia, tornar-se meramente representativa perante as políticas sociais do capital, transformando a relação social dos sujeitos da Ciência com o conhecimento. Apropriarse das teses argumentativas comprovadas de outrem deixa de possuir o agravante moral do desrespeito da integridade de uma pessoa, mas transforma-se em furto indevido, ou em empréstimo forçado. O fato de postergar ao conhecimento o predicado de propriedade privada acarreta no deslocamento de todos os vícios e fraudes das relações mercadológicas existentes na sociedade contemporânea, deslegitimando a dignidade e o esforço de elaboração autoral.

Nesse panorama, torna-se elementar que os parâmetros científicos vislumbrem de forma efetiva sua responsabilidade social na esfera política, possibilitando condições de contribuição ao âmbito instrutivo formal e informal. Segundo Candotti (2002), a cultura, as tradições locais e os hábitos que compõem um núcleo social devem ser levados em consideração pelas ciências e seus profissionais. Por consequência, a tríade ciência, tecnologia e sociedade prescinde da apreensão das condições locais, individuais e metodológicas que cada núcleo particular possui, levando-se em consideração as idiossincrasias organizacionais.

$\mathrm{Na}$ mesma direção interpretativa acerca do papel da divulgação da ciência, Paludo (2001) sugere aos cientistas a concatenação dos âmbitos formais e informais da difusão das pesquisas, com o propósito de potencializar o conhecimento e a transformação social, viabilizando condições de superação das contradições entre teoria e prática sempre presentes na leitura social do trabalho acadêmico:

Admite-se e deseja-se, nestes novos tempos, que esta concepção de educação do popular não seja adequada exclusivamente para os espaços não-formais de educação. Se aposta na sua capacidade de disputa na rede oficial de ensino, embora se admita que sua ressignificação e fecundidade sejam maiores nos espaços não-formais, visto que muito mais liberta das amarras que prendem os espaços formais e porque exercida por indivíduos que possuem por ela uma opção clara, o que não significa estar, como tudo na vida, isenta de contradições. Considera-se que esta tarefa é mais fácil de ser levada a 
efeito quando existem governos democráticos e populares, mas também quando eles não existem, admite-se a possibilidade, desde que os sujeitos educadores queiram orientar as práticas educativas por esta perspectiva, se disponham a "entrar na luta" e a projetar e vivenciar outro modo de fazer educação das classes subalternas. (PALUDO, 2001, p.206-207).

Esse "outro modo" de fazer educação, apontado pela citação acima, tem o propósito de superar a monocultura do saber e proporcionar condições factíveis que eliminem todo cerceamento das práticas educativas tradicionais. Assim, cria-se a demanda de organizações sociais e científicas capazes de democratizar o conhecimento contundente com as necessidades mais elementares, incentivando o enriquecimento do universo de informações, experiências e observações, a fim de que os mesmos tornemse credíveis e superem a subalternidade do saber reproduzido no plágio e na incapacidade da autenticidade do conhecimento acadêmico.

\section{Alternativas de superação do plágio científico como produtividade meramente reprodutora}

Para compreender os mecanismos com os quais o combate ao plágio se revela possível no sistema de produção científica do conhecimento, apresentam-se nesse tópico algumas características do sistema científico que são norteadoras da referida discussão. Uma das alternativas para ressignificar a realidade científica da autonomia e autoria dos sujeitos na construção cognitiva encontra-se na proposta de Boaventura de Souza Santos na Ecologia dos Saberes (SANTOS, 1995), instrumento conceitual metodológico que tem como escopo eleger a multiplicidade das relações humanas legitimamente no diálogo global não globalizante. Identificar outros saberes, de modo criterioso e elucidativo, tornando cada vez mais significativa a existência do outro, constitui um dos pilares para a reinvenção da emancipação social (SANTOS; MENESES, 2010), seja pelos movimentos sociais e organizações não governamentais, seja na esfera individual, na capacidade de promoção da autorreflexão.

Desse modo, as afirmações de Boaventura de Souza Santos (2010) sobre a relação ciência e sociedade é novamente reafirmada. Na sua exegese aponta-se para um fato incômodo ao meio acadêmico: o desconhecimento das necessidades e configurações da sociedade geral por parte dos cientistas. Por consequência, a esfera acadêmica distancia-se de sua própria responsabilidade e justificativa social, criando um distanciamento imensurável e incipiente entre a elaboração do conhecimento e sua efetividade prática. Institucionalizam-se condições de constrangimento para todos os 
âmbitos que não (re)produzam o método científico, sem considerar o propósito básico de fomento das condições ascensão social. Como consequência, as graduações e processos de formação universitária perdem seu foco praxiológico, ratificando condições de um contexto de ilegalidade e irresponsabilidade acadêmica, culminado pelo plágio.

Para mudar esse quadro preocupante, algumas pesquisas e textos acadêmicos proporcionam possibilidades de superação dos paradigmas da ciência tradicional. A educação demanda de novos encaminhamentos com o propósito de tornar-se decisiva e fundamental para a sociedade, e não reduzir-se à cópia irrefletida do conhecimento, principal endosso cultural da cópia/cola. Sobrepujar o mito moderno da ciência apresenta-se como uma tarefa árdua, principalmente quando se pondera os interesses desiguais nas ações locais e globais. A transformação social poderá ser viabilizada apenas por interferência de uma educação estruturada e composta por profissionais com competência no domínio dos conteúdos científicos e perpassados por uma visão política engajada.

Nesse contexto, Maria Eduarda do Nascimento Vaz Moniz dos Santos (1999) aponta para a necessidade de diferenciar e transformar a concepção de educação sobre ciência, restrita aos aspectos metacientíficos abstratos cuja aplicabilidade torna-se insossa, para uma educação pela ciência, apta a apontar e resolver problemas da vida com o aparato do ensino científico engajado na dimensão formativa e cultural. Evidencia-se a necessidade premente de proporcionar características pragmáticas à educação científica, propiciando uma nova organização que tramite pelos intentos da negação da reprodução social em nome da pluralização coletiva do método, dos instrumentos e dos problemas investigativos que surgem na eleição das experiências credíveis.

Com esse intuito de superar o modo linear de desenvolver a Ciência, Maria Eduarda do Nascimento V. M. dos Santos (1999) referenda também alguns requisitos para repensar as limitações científicas contemporâneas. $\mathrm{Na}$ defesa da transdisciplinaridade, do conhecimento contextual e diversidade e heterogeneidade organizacional, demonstram-se as possibilidades de superar os tradicionalismos acadêmicos na direção de alguns objetivos claros: estímulo da iniciativa, criatividade e capacitação científica dos pesquisadores, além da criação de mecanismos metodológicos que agreguem as demandas sociais com as investigações científicas desenvolvidas. 
O meio cultural contemporâneo tem um peso significativo nas mudanças no ethos da ciência que, por sua vez se repercutem em mudanças no ethos social. Consequentemente, a falta de atualização dos discursos curriculares, quando 'esquecem' essas influências recíprocas, quando continuam a perpetuar 'velhas' ideias incontroversas e estereotipadas sobre usos e costumes da ciência e os tradicionais conteúdos científicos canônicos, quando silenciam o carácter operatório da ciência atual, como um dos seus aspectos mais marcantes, quando não procuram trazer para o ensino das ciências valores relacionados com contextos de ação, quando inviabilizam a desejada projeção do ensino das ciências para o contexto do mundo real, ocasionam perdas educacionais significativas. (SANTOS, M., 1999, p.6).

Outrossim, esses novos desafios que a educação científica de superação do plágio e da descrença do conhecimento sistematizado enfrenta demonstram as complexidades que o sistema acadêmico precisa levar em consideração. O fundamento da política social vinculada com a pesquisa possui a necessidade de desvelar as heranças da concepção reducionista e mecanicista da ciência positivista, ainda presentes nas diretrizes que compõem o processo burocrático educacional (SANTOS, B., 2010). Fazse fundamental repensar os critérios de avaliação de programas de divulgação científica, ainda precários e orientados pelo alto nível de hierarquização do conhecimento em voga, a fim de garantir condições de equidade social, formulando políticas e planos nacionais capazes de dispor a mobilização do conhecimento em diferentes campos sociais, superando a desigualdade de distribuição de recursos basilares na cidadania plena almejada.

Os debates das ciências, sobretudo humanas, cuja vertente seria supostamente investida na autonomia social e no questionamento da realidade, assumem uma perspectiva tal que, no decurso da regulamentação rígida epistemologicamente engessada, tornam-se um modelo único e subserviente aos procedimentos burocráticos. A função pedagógica da universidade é controlada na burocracia, pelo intermédio da qual as agências de financiamento são determinantes no despotismo ideológico, aniquilando dessa maneira toda ponderação sobre a própria realidade no exame dos conteúdos e intentos da mesma. A Ciência é convertida num pressuposto do progresso na medida em que a hierarquia, a eficiência e a especialização universitária são definidas por um mecanismo exterior do ensino, cujos propósitos encontram-se viciados no contexto da (re)produção.

[...] o capitalismo global, mais que um modo de produção, é hoje um regime cultural e civilizacional, portanto, estende cada vez mais os seus tentáculos a domínios que dificilmente se concebem como 
capitalistas, da família à religião, da gestão do tempo à capacidade de concentração, da concepção de tempo livre às relações com os que nos estão mais próximos, da avaliação do mérito científico à avaliação moral dos comportamentos que nos afetam. Lutar contra uma dominação cada vez mais polifacetada significa perversamente lutar contra a indefinição entre quem domina e quem é dominado, e, muitas vezes, lutar contra nós próprios. (SANTOS; MENESES, 2010, p.18).

Doravante a universidade é peça fundamental ao processo de legitimação do paradigma científico de controle. E isso de várias maneiras: desenvolvendo conhecimentos técnicos, científicos e informacionais, cuja aplicação no sistema produtivo o torna mais eficiente ou permite agregar valores aos serviços e mercadorias, tornando-os mais rentáveis, auxiliando na formação de recursos humanos necessários às demandas liberais e, sobretudo, disseminando um conjunto de crenças, valores, atitudes ou hábitos necessários para perfilhar a mentalidade acrítica da maioria das pessoas detentoras da força de trabalho.

Considerando o quadro exposto, é preciso ressaltar que a universidade ou mesmo o sistema educacional institucional não estão imunes às tensões sociais e disputas que se realizam no contexto de contradições da sociedade moderna. Tampouco ela, a universidade, constitui-se em mimese da sociedade onde está ancorada. Antes, a mesma é expressão tanto das tensões sociais que ocorrem na sociedade, quanto do processo civilizador em curso.

Nesse sentido, uma das alternativas de superação da produção paradigmática moderna encontra-se na percepção credível dos parâmetros epistemológicos até então ignorados. Essa prática parte de um procedimento conceitual específico, cuja aplicabilidade estende-se aos diversos contextos alternativos da legitimação das relações político-sociais, com particularidades dialógicas básicas:

Trata-se do conjunto de intervenções epistemológicas que denunciam a supressão dos saberes levada a cabo, ao longo dos últimos séculos, pela norma epistemológica dominante, valorizam os saberes que resistiram com êxito e as reflexões que estes têm produzido e investigam as condições de um diálogo horizontal entre conhecimentos. A esse diálogo entre saberes chamamos ecologias de saberes. (SANTOS; MENESES, 2010, p.7).

O conhecimento científico deixa de ser o único saber valorado, mas um dos elementos da diversidade plural do mundo. No paradigma da Ecologia dos saberes, a aprendizagem é preconizada na reciprocidade das culturas e dos conhecimentos múltiplos que se entrecruzam precipuamente. Por consequência, as experiências individuais são otimizadas e as práticas sociais alternativas disponibilizadas. A utopia 
do interconhecimento não se restringe a mera representação da realidade, mas se amplia na direta intervenção do real (SANTOS, B., 2007).

\section{Conclusões}

Uma das principais hipóteses a ser corroborada na conclusão do presente trabalho é a proposta de reconsiderar a noção de objetividade científica no que se refere ao ato de situar as ciências em geral na complexidade do plágio enquanto problemática social. Cabe à Ciência repensar não apenas seus métodos ou técnicas de pesquisa, mas questionar a capacidade de autonomia potencializada nas suas conclusões. Da mesma forma, argumentos sobre disposições éticas baseadas em uma perspectiva de conscientização profissional em detrimento do descaso com a investigação científica, demonstram condições insuficientes para a comunidade acadêmica em geral.

O presente trabalho se dedicou a uma reflexão sobre o vínculo entre a preleção capitalista sobre a produção acadêmica e a presença do plágio como sintoma decisivo na demanda por mudanças paradigmáticas do saber científico. Perante as instituições sociais, as ciências humanas impõem à universidade o fomento da produção do capital, em dois polos extremos: de um lado a exigência de produção de artigos e livros especializados para desempenhar atividades na produção, do outro, um grupo intelectualmente letárgico no que concerne ao debate emancipador do conhecimento, cuja perspectiva de desenvolvimento intelectual é praticamente inexistente na medida em que copia de modo inapropriado as conclusões de pesquisas alheias.

Os aportes teóricos que fundamentaram tais aproximações partiram de duas dimensões comuns: a viabilização do sujeito enquanto indivíduo dominado pelas regras intrínsecas e extrínsecas na coação de sua compreensão social; e a Ecologia dos Saberes de Boaventura de Souza Santos, crítico ávido do monismo metodológico acadêmico e da unicidade do real.

Evidencia-se que discussões e pesquisas sobre o plágio e a ética na esfera científica ganham força na conjuntura desenhada pela produção contemporânea do conhecimento. Uma mudança de postura na publicação de artigos, com o auxílio de softwares e de todos os instrumentos disponíveis para a viabilização de condutas morais coparticipes do desenvolvimento social tornam-se estratégias pertinentes de tomada da consciência do papel do cientista perante a sociedade e, principalmente, perante seus pares, aqueles com quem deve exercer vínculos de respeito e consideração em sua plenitude. 
Atualmente, o pesquisador é pressionado pelos critérios da CAPES e por outras agências de fomento no que tange à avaliação de projetos e programas de pósgraduação. As exigências pela demonstração pública dos resultados quantitativos em detrimento aos qualitativos podem ocasionar situações limítrofes entre o bom senso e o descaso ético.

Consequentemente, faz-se primordial repensar as práticas da avaliação científica e formativa que visem ao esclarecimento e à conscientização das consequências sociais do uso indevido de referências, pois os mesmos representam o desnorteamento ético da divulgação das pesquisas e a invalidação do trabalho dos pesquisadores. A prática científica não pode restringir-se à reprodução do sistema antagônico de injustiças, principalmente se o foco é o acesso ao conhecimento necessário para as relações de socialização do conhecimento.

Partindo dessas análises, pode-se destacar que a cientificidade e a inteligibilidade das pesquisas acadêmicas encontram-se em um momento histórico de reestruturação no que se refere as suas diretrizes de divulgação e apropriação de conhecimentos. Comissões editoriais, projetos de integridade da pesquisa viabilizados pelas agências de fomento e a comunidade científica em seu todo voltam-se para a necessidade de uma retomada epistêmica da produção textual, que perpasse os complexidades da tecnologia de acesso às informações e impulsione o desenvolvimento social dos instrumentos e dos problemas investigativos que surgem na eleição das experiências científicas factíveis.

\section{FRAUD AND ACCOUNTABILITY IN RESEARCH STS: RESEARCH OF APPEARANCES}


ABSTRACT: In contemporary times, we can see the high cross- index information with the academic processes of research. The digital age provides a wide area of expertise between cultures, theories and ways of thinking, democratizing access to the thoughts and ideas, enabling the dissemination of knowledge and at the same time, allowing for the promotion of reckless practices based on plagiarism. This paper is a literature review article in the STS domain that analyzes the conditions of possibility of science and the subject for it consists in the discussion of the notions of fraud and responsibility that they have. This research aims to elucidate what are the implications of plagiarism prescribes for the line of action of science and technology. Thus, the work is divided into three stages: initially, will seek to clarify the concepts, ethics, responsibility and plagiarism, building apparatus for the following two moments, the survey of the main consequences of the end of autonomy and scientific authorship in the statement of disbelief cognitive subject and the third time, to present the possibilities of rethinking reordering instruments of academic practices that seek to significantly be appropriate in an authentic way, innovative and based on the social development of research in STS.

KEYWORDS: Science-Technology-Society (STS). Critical thought. Social responsibility of science.

\section{REFERENCIAS}

BRASIL. Coordenação de Aperfeiçoamento de Pessoal de Nível Superior [CAPES]. Orientações CAPES no combate ao plágio. Disponível em:

$<$ http://www.capes.gov.br/images/stories/download/diversos/OrientacoesCapes_Combat eAoPlagio.pdf>. Acesso em: 25 out. 2014.

CANDOTTI, E. Ciência na educação popular. In: MASSARANI, L.; MOREIRA, I. C.; BRITO, F. (Org.). Ciência e público: caminhos da divulgação científica no Brasil. Rio de Janeiro: Casa da Ciência: Centro Cultural de Ciência e Tecnologia da UFRJ, 2002. p.15-23.

CASTRO, M.; SILVA, O. Intertextualidade ou plágio? considerações teórico-práticas. Signótica, Goiânia, v.2, n.1, p.153-161, 1990.

CNPQ. Relatório da Comissão de Integridade de Pesquisa do CNPq. Disponível em: <http://www.cnpq.br/documents/10157/a8927840-2b8f-43b9-8962-5a2ccfa74dda>. Acesso em: 25 out. 2014a.

CNPQ. Resolução Normativa n⿳0 06/2012. Disponível em: <http://www.cnpq.br/web/guest/view/-/journal_content/56_INSTANCE_0oED/ 10157/106200>. Acesso em: 25 out. 2014b.

FUNDAÇÃO DE AMPARO S PESQUISA DO ESTADO DE SÃO PAULO [FAPESP]. Código de boas práticas da FAPESP. Disponível em: <http://www.fapesp.br/boaspraticas>. Acesso em: 25 out. 2014.

PALUDO. Educação popular em busca de alternativas: uma leitura desde o campo democrático e popular. Porto Alegre: Tomo editorial: Camp, 2001. 
RUSSO, M. Ética e integridade na ciência: da responsabilidade do cientista à responsabilidade coletiva. Estudos avançados, São Paulo, v.28, n.80, p.189-198, abr. 2014. Disponível em: <http://www.scielo.br/scielo.php?script=sci_arttext\&pid=S0103$40142014000100016 \& \operatorname{lng}=$ pt\&nrm=iso $>$. Acesso em: 25 out. 2014.

SANTOS, Boaventura de Souza. Um discurso sobre as ciências. 7.ed. São Paulo: Cortez, 2010.

. Renovar a teoria crítica e reinventar a participação social. São Paulo: Boitempo, 2007. Introdução a uma ciência pós-moderna. 4.ed. Porto: Afrontamento, 1995.

SANTOS, Boaventura de Souza; MENESES, Maria Paula (Org.). Epistemologias do sul. São Paulo: Cortez, 2010.

SANTOS, Maria Eduarda do Nascimento Vaz Moniz dos. Encruzilhadas de mudança no limiar do século XXI: co-construção do saber científico e da cidadania via ensino CTS de ciências. In: ENCONTRO NACIONAL DE PESQUISA EM EDUCAÇÃO EM CIÊNCIAS, 2.,Valinhos, 1999. Anais... Valinhos: ABRAPEC, 1999. Disponível em: <http://www.nutes.ufrj.br/abrapec/iienpec/Dados/trabalhos/A39.pdf>. Acesso em: 26 nov. 2014.

SHAPIN, S. Science and the modern world. In: HACKETT, E. J. et al. The handbook of science and technology studies. Cambridge:The MIT Press, 2008. p.433-448.

SILVA, O. S. F. Entre o plágio e a autoria: qual o papel da universidade? Revista Brasileira de Educação, Rio de Janeiro, v.13, n.38, p.357-368, ago. 2008. Disponível em: <http://www.scielo.br/scielo.php?script=sci_arttext\&pid=S1413$24782008000200012 \& \operatorname{lng}=$ pt\&nrm=iso $>$. Acesso em: 25 out. 2014.

VASCONCELOS, S. M. R. O plágio na comunidade científica: questões culturais e linguísticas. Ciência e Cultura, São Paulo, v.59, n.3, p.4-5, 2007.

VELUDO-DE-OLIVEIRA, T. et al. Cola, plágio e outras práticas acadêmicas desonestas: um estudo quantitativo-descritivo sobre o comportamento de alunos de graduação e pós-graduação da área de negócios. RAM: Revista de Administração Mackenzie, São Paulo, v.15, n.1, p.73-97, fev. 2014. Disponível em: < http://www.scielo.br/pdf/ram/v15n1/a04v15n1.pdf > . Acesso em: 25 out. 2014. 